\title{
A return to virtue ethics: Virtue ethics, cognitive science and character education
}

\author{
Author: \\ Nico J. Grönum ${ }^{1}$ \\ Affiliation: \\ ${ }^{1}$ Department Science of \\ Religion and Missiology, \\ University of Pretoria, \\ South Africa \\ Correspondence to: \\ Nico Grönum \\ Email: \\ nico.gronum@up.ac.za \\ Postal address: \\ Private Bag X2, Gauteng \\ 0109, South Africa \\ Dates: \\ Received: 28 Jan. 2015 \\ Accepted: 26 May 2015 \\ Published: 14 Aug. 2015 \\ How to cite this article: \\ Grönum, N.J., 2015, 'A return \\ to virtue ethics: Virtue \\ ethics, cognitive science \\ and character education', \\ Verbum et Ecclesia 36(1), Art. \\ \#1413, 6 pages. http://dx.doi. \\ org/10.4102/ve.v36i1.1413

\section{Copyright:} \\ C 2015. The Authors. \\ Licensee: AOSIS \\ OpenJournals. This work is \\ licensed under the Creative \\ Commons Attribution \\ License.
}

Read online:

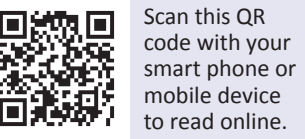

Morality in church and society is a burning issue. Church leaders know that the challenges are both formidable and urgent, yet finding solutions is easier said than done. The question this article asks is how can we educate for character? In the past, deontology or rule ethics reigned supreme, virtue ethics, however, gradually made a comeback. Currently virtue ethics is an important part of character education in the United States of America, especially with schools affiliated with churches. Recent insights provided by researchers focusing on cognitive science (working from the vantage point of cognitive and social psychology) have managed to prove the legitimacy of virtue ethics but remind us that virtues must not be drilled into children; moral deliberation and imagination must be fostered in order to cultivate individuals with moral character that will be able to reflect on their own received tradition. I provide an example of such a method of education when I explain Integrative Ethical Education as formulated by Darcia Narvaez.

Intradisciplinary and/or interdisciplinary implications: This article confirms the validity of virtue ethics but calls for a change in the standard method of character education that exclusively emphasises knowledge of the Bible and strict obedience to the morals that the local community derives from the Bible, to an approach that also encourages teachers to help foster independent thinkers neither lacking in character nor the ability to reflect critically on their own tradition. I do believe that such a change is possible as was recently shown by the implementation of Darcia Narvaez's Integrative Ethical Education in the United States of America.

\section{Introduction}

Joseph Kotva (1996) supplies us with a handy definition of virtue ethics:

Virtue ethics has a tripartite structure: (1) human-nature-as-it-exists; (2) human-nature-as-it-could-be; and (3) those habits, capacities, interests, inclinations, precepts, injunctions, and prohibitions that will move us from point one to point two. (p. 17)

A good way of understanding virtue ethics is to contrast it with deontological ethics. Deontology, or rule based ethics, held sway during the latter stages of the Enlightenment with Immanuel Kant well into the 20th century. Alexander and Moore (2012) define deontological ethics as:

The word deontology derives from the Greek words for duty (deon) and science (or study) of (logos). In contemporary moral philosophy, deontology is one of those kinds of normative theories regarding which choices are morally required, forbidden, or permitted. In other words, deontology falls within the domain of moral theories that guide and assess our choices of what we ought to do (deontic theories), in contrast to (aretaic [virtue] theories) that—fundamentally, at least—guide and assess what kind of person (in terms of character traits) we are and should be. (n.p.)

Whilst deontology focuses on the norms that determine a person's duties, virtue ethics focuses on the agent and what the agent needs to have (virtues) or rather be (virtuous) to achieve the goal. Important to note that although they differ in focus, deontology and virtue ethics are not opposites of one another. The opposite of deontology, for example, is consequentialist ethics. ${ }^{1}$

Looking at virtue ethics, we may immediately ask how it fits in with Protestant Calvinist Christianity. Do I need to acquire habits to become somebody? Is it not up to God to make me that somebody? You may say that I view prayer, worship and Bible study as integral to the change

1.Alexander and Moore (2012) define the difference as follows: 'Consequentialists hold that choices - acts and/or intentions - are to be morally assessed solely by the states of affairs they bring about ... In contrast to consequentialist theories, deontological theories judge the morality of choices by criteria different from the states of affairs those choices bring about. The most familiar forms of deontology, and also the forms presenting the greatest contrast to consequentialism, hold that some choices cannot be justified by their effects that no matter how morally good their consequences, some choices are morally forbidden. On such familiar deontological accounts of morality, agents cannot make certain wrongful choices even if by doing so the number of those exact kinds of wrongful choices will of morality, agents cannot make certain wrongful choices even if by doing so the number of those exact kinds of wrongful choices will
be minimized (because other agents will be prevented from engaging in similar wrongful choices). For such deontologists, what makes a choice right is its conformity with a moral norm. Such norms are to be simply obeyed by each moral agent; such norm-keepings are not to be maximized by each agent'. 
God works in me, yet it is he who works the change. To this, N.T. Wright (2010), a respected authority on the apostle Paul, says:

There is the sequence: grace, which meets us where we are but is not content to let us remain where we are, followed by direction and guidance to enable us to acquire the right habits to replace the wrong ones. (p. 63)

Faith is therefore not only an act of believing but also of obedience, of being directed and guided to acquire and develop the right habits. In other words, a strong case can be made for the place of virtue ethics within the divine economy.

As is apparent in Wright's discussion, virtue ethics certainly has its place within the New Testament. In fact, virtue ethics was very popular during ancient times with the Greek philosopher, Aristotle, as one of its pioneers. However, it has seen a loss of prestige during modern times. Fortunately, virtue ethics has made a comeback during the latter stages of the 20th century.

Currently virtue ethics is an important part of character education in the United States of America, especially with schools affiliated with churches. Recent insights provided by researchers focusing on cognitive science (working from the vantage point of cognitive and social psychology) do prove the legitimacy of virtue ethics but reminds us that virtues must not be drilled into children; moral deliberation and imagination must be fostered in an attempt to cultivate an individual with moral character that will be able to reflect on his or her own tradition (Narvaez 2006:711).

A virtue ethics infused with insights from cognitive science forms the heart of Narvaez's approach to character education called Integrative Ethical Education (IEE). I will consequently turn to IEE as an example of a virtue ethics approach that also pays close attention to moral reflection and deliberation and moral imagination.

In this article, I will briefly trace the rise in popularity of virtue ethics, describe the way cognitive science views virtue ethics and character education, and give an account of IEE that shows how virtue is cultivated alongside the child's ability to reason.

\section{The rise of virtue ethics}

Virtue ethics has seen a remarkable rise in popularity over the last three to four decades with proponents such as Alasdair MacIntyre (1981), Stanley Hauerwas (1983) and N.T. Wright (2010). Joseph Kotva (1996) ascribes the rise in popularity to:

[...] three factors in particular have helped renew interest in virtue ethics: (1) the widespread perception that our society is in moral crisis, (2) the rise of historical consciousness, and (3) the failure of modern ethical theories to provide a complete picture of human moral experience. (p. 6)

The first and third reasons are more or less self-explanatory. Some believe modern day people lack character. Furthermore, many believe that rationalist rule based ethical approaches (deontological ethics) have failed to address current moral maladies. Instead, it has reduced people to rational agents, ignoring, for example, the role of emotion in ethical decisionmaking.

The second reason, the rise in historical consciousness, Kotva (1996) describes as:

[...] another factor helping to renew interest in virtue ethics is the growth in the second half of the twentieth century of what might loosely be called 'historical consciousness'. Moral theologians and philosophers have increasingly recognized the relevance of our historical nature. We are historical creatures, situated in specific historical and cultural contexts with particular beliefs, practices, and commitments. All knowledge, including moral knowledge, is historically grounded and at some level informed by the setting from within which it is known. The growing realization of history's relevance is altering ethical theory in at least two general ways: (1) limiting the role and status of rules, and (2) increasing the attention given to one's context. (p. 8)

Tempted as we may be, the rise in historical consciousness is not the sole achievement of French postmodernist thinkers. We may be conditioned to jump to postmodernism when we are confronted with descriptions such as Kotva's above stating that 'we are historical creatures, situated in specific historical and cultural contexts with particular beliefs, practices, and commitments'. However, the realisation of history's relevance did not begin with postmodern thought, neither is postmodernism the chief contributor to us recognising 'the relevance of our historical nature'. That honour belongs to German Historicism. Frederick Beiser (2011) defines German Historicism as:

Roughly, to historicize our thinking means to recognize that everything in the human world - culture, values, institutions, practices, rationality - is made by history, so that nothing has an eternal form, permanent essence or constant identity which transcends historical change. The historicist holds, therefore, that the essence, identity or nature of everything in the human world is made by history, so that it is entirely the product of the particular historical processes that brought it into being. (p. 2)

Historicism is one of two approaches to knowledge that emerges from the Enlightenment. John Leavitt (2011) calls these two approaches universalism and essentialism (historicism). In short, a universalist approach wants to unearth the underlying order of existence, it asks questions such as:

- What is the same?

- What kind of universal patterns can we distinguish?

- What laws are there that describe existence?

An essentialist (or historicist) approach do not believe in a underlying patterns or sets of laws that describe us all, rather each civilization has a unique essence or character found in that civilization's language, culture and context. If you want to understand that civilization, you must understand its essence. The influence of this approach would be immense. Sheila Greeve Davaney (2000) writes as follows: 
It has become axiomatic in the late twentieth century to acknowledge that human beings are neither residents of everywhere nor nowhere but are situated within particular locales demarcated by distinctive languages, worldviews, political and economic structures, and social, religious, and ethical configurations. Moreover, this acknowledgement of the localized character of experience and knowledge has contained the recognition that our current context is the product of the vagaries of complex and varied historical processes that have proceeded our era and of our own contemporary responses to and transformations of these processes. Human historicity, thus, entails both being constituted by our past and context and being agential contributors to new historical realities. (p. 1)

What may be the difference between yesterday's historicism and today's postmodernism? It would appear, if one looks at proponents of historicism such as Johann Herder (1744-1803) that they believed it possible to get to know another culture. In other words, knowledge was possible, we could penetrate another language and its cultural concepts, in so doing getting to know them as they are (Forster 2010; Sikka 2011).

With some postmodern scholars the trend is to say that knowledge is not possible, rather what we say reflects more on ourselves than it says anything worthwhile about another culture (read Arthur Frank's [2010] discussion of windows as portals actually being mirrors). It is therefore understandable if many point to what is commonly referred to as postmodernism as the agent that relativised ethics, the chief influence of historicism may however not be ignored.

From this, an important question emerges in terms of what to do when there are no universal moral rules? In After virtue, a study in moral theory (1981), Alasdair MacIntyre addresses the issue through the introduction of virtue ethics and the concept of a practice.

MacIntyre (1981:187) explains that there are many different kinds of practices; for example, playing chess, painting a portrait, farming, making war, educating people, and so forth. Each of these can be called a practice. Each of these practices has their ends and goals and the skills needed to realise these ends and goals. These ends and goals as well as skills have been determined by a long history of expert practitioners in the field. After years and years of trying to achieve the goals set by practitioners in the field, experts have come to learn what skills are needed to meet them. If you want to join a practice, you will have to submit yourself to the practitioners, letting them teach you the skills necessary to realise the ends and goals of the practice. MacIntyre's brand of virtue ethics would prove to be very popular in time when essentialism as approach to knowledge was (and still is) very influential.

\section{Virtue ethics and cognitive science}

The human mind has been studied and discussed from antiquity, as is evident in philosophy. However, psychology, as we know it today, developed during the late 1800s pioneered by several prominent figures such as Wilhelm Wundt, William James and Sigmund Freud. From early on, the need was expressed to treat psychology as an empirical science. If this was the case, psychology had to focus on behaviour, because inner mental states could not be observed. From this, in the early 1900s arose the emphasis on the study of behaviour in psychology (McManus \& Butler 2014).

The focus again started to shift during the 1950s back to the minds inner workings. In this regard, Paul Thagard (2014) defines cognitive science as follows:

Cognitive science is the interdisciplinary study of mind and intelligence, embracing philosophy, psychology, artificial intelligence, neuroscience, linguistics, and anthropology. Its intellectual origins are in the mid-1950s when researchers in several fields began to develop theories of mind based on complex representations and computational procedures. Its organizational origins are in the mid-1970s when the Cognitive Science Society was formed and the journal Cognitive Science began. Since then, more than ninety universities in North America, Europe, Asia, and Australia have established cognitive science programs, and many others have instituted courses in cognitive science. (n.p.)

Cognitive science started to treat the mind as a computational device with five key elements (some ancient) at its heart; these are categories, concepts, propositions, schemata and cultural models. When I refer to cognitive science, it is from the vantage point of cognitive psychology, social psychology and social cognition.

Psychologists Douglas Medin and Lance Rips (2005) are generally considered authorities on categorisation. Both these psychologists are adamant that categories (or mental representations) and categorisation are most basic to human cognition. In itself, categorisation is nothing new. We only need to look at Aristotle's use of categories.

That being said, Medin and Rips (2005:42) pointed out that without categories we would constantly have to stop and investigate everything we see and experience as if it is some unknown entity. Categories help us avoid this. Once we have identified an object (e.g. a Mercedes Benz) to be part of a category (i.e. a car) we can bring our knowledge of the category to bear on the object. In this sense we have instant knowledge of the Mercedes Benz and we can predict certain aspects of it (it will be able to go forwards and backwards etc.). In other words, with categories we can quickly and effortlessly make sense of what we encounter in our daily lives. Some debate exists as to what extent categories are innate or not. Others want to know more about the rules of membership. Does something become a member of a category because it shares essential characteristics with other members of that category (classical view: Aristotle and essentialism) or is it because it shares a trait with the prototype (probabilistic view: Wittgenstein and prototypes) that best exemplifies the category.

When we bring our categories under words (lexicalise), we have concepts. In other words, the word or concept 'dog' (i.e. everything we perceive and can infer of dogness) refers to 
the mental representation or category 'dog' (Medin \& Rips 2005:55; Sloutsky 2010:1245).

Seeing that a proposition consists of concepts, consider the following proposition: 'the dog is big'. From propositions, we start to build a schema or schemata, as Cherry (2010) explains:

Concepts are building blocks, so your brain uses them to build. Concepts are put together to create propositions, which are units of meaning expressing a single idea. Come up with a sentence, any sentence. This is a proposition. Propositions that are related are linked and create a network of knowledge and information that makes up a schema. A schema is basically a mental model of what you expect from a particular encounter. These schemata are built using your experience and concepts and allow you to have certain expectations when you encounter ideas, beliefs, situations, or people in your environment. (n.p.)

For example, when I arrive at a restaurant, I automatically know what to do because of my 'dining-out schema'. I do not constantly stop and question everything, thinking about what to do next. When I am seated at my table I use my schema of a salt pot, so I know instinctively not only what a salt pot looks like (i.e. I have a concept of a salt pot) but also know how to use a salt pot. In this sense, we have schemata within a larger schema.

Pennington (2012) states that we generally use schemata because we are cognitive misers. In reality, we do not have the time, the capacity or the will to expend all the time and effort to stop, examine and think about everything we encounter. Schemata as frameworks or mental models made up of propositions, not only tell us what an object or situation is, but also how to behave when encountering it and what to expect from it. Essentially, they are mental shortcuts.

People are cognitive misers; we do not, for the most part, gather principles and when confronted with a situation, stop to think and determine the application of those principles and then act. We mostly think about what we need to do when we are confronted with unknown situations. Unfortunately all this deliberate thinking expends mental energy and takes time. Luckily for us, we spend most our time in circumstances familiar to us. When we are in familiar circumstances schemata guide our behaviour as we go through life on autopilot (Bennardo \& De Munck 2014). This sounds remarkably similar to a description of virtue ethics.

In his discussion of Christian character in After you believe: Why Christian character matters, N.T. Wright starts with the story of pilot captain Sullenberger who, after striking birds shortly after takeoff, managed to land an Airbus passenger airplane in the Hudson river in New York. Wright (2010) then says:

You could call it the power of right habits. You might say it was the result of many years of training and experience. You could call it 'character', as we have done so far in this book. Ancient writers had a word for it: virtue. (p. 20)
One could say captain Sullenberger had well-developed schemata (he was a gliding instructor) exercised through years of flying. When the time came, he reacted, drawing on tacit knowledge (a large part of schemata) gained through a long career.

How does a cognitive scientist differ in their approach to virtue or character education from approaches that gained popularity during the latter stages of the 20th century in the United States of America? Besides the fact that cognitive scientists consider virtue ethics from a universalist and not a essentialist approach, Narvaez (2006:711) objects to the 'outdated teaching methods such as exhortation, memorisation, and punishment, methods that make incorrect assumptions about how people learn'.

With virtue or character education, the focus is usually on mastering a particular set of virtues or habits. The temptation then, is to adopt a 'do not think, obey and copy!' approach. Alfie Kohn (1997), however, strongly objects to methods that 'drill students in specific behaviors rather than to engage them in deep, critical reflection about certain ways of being'. Mark Johnson (2014:32) also points to the fact that whilst it is important to learn the skills needed to excel within practices (MacIntyre's practices), it is important not to blindly reproduce them. We also need to be able to reflect critically on the inherited tradition otherwise 'there can be no intelligent moral growth and transformation' (Johnson 2014:32).

Johnson is furthermore convinced that moral deliberation, and not only instinctive behaviour guided by schemata, plays an important role in determining our behaviour. Although, for the most part, we act instinctively, we do reflect on our behaviour, especially when our behaviour is deemed unsuccessful or unacceptable within our society. In this case, we define the problem and then start to reason, or as Johnson (2014:92) - well-known in linguistic circles puts it, 'explore in imagination' how best to act in future. Behaviour is not only instinctual. Reason, or imagination, has a very definite place in developing and changing our schemata.

\section{Integrative ethical education}

So far, we can say the following: when we find ourselves in unknown circumstances, we stop and think what to do. This expends mental energy and takes time. When we are in familiar circumstances, schemata guide our behaviour as we go through life on autopilot. We usually reflect on our behaviour after the fact, especially when our social surroundings change or when we engage in unsuccessful behaviour. When this happens, we engage in moral deliberation. Through this process of reflection, we can alter or improve our schemata (Bennardo \& Munck 2014).

Two important aspects emerges from this brief treatment of recent insights in cognitive science viewed from the vantage point of cognitive psychology, social psychology and social 
cognition, that is our ability to function on autopilot and the need for moral deliberation and imagination.

How do we educate for behaviour change? If we acquire schemata through our interaction with the world, through the guidance, experiences and stories that our environment offers, and if we alter and improve them through moral deliberation, Lev Vygotsky's idea of the zone of proximal development may be useful. This well-known concept has mentors aiding mentees to grasp concepts just beyond their reach, helping them with action and emotional management, supporting them as they grow (Hammond, Austin, Orcutt \& Rosso 2001:9).

In this sense, mentors can be very effective support to mentees engaging in moral deliberation. This, more or less, lies at the heart of Darcia Narvaez's Integrative Ethical Education (a moral psychologist at the University of Notre Dame). Darcia Narvaez implemented IEE in the Minnesota Community Voices and Character Education Project with great success. Graciously Narvaez and her colleagues have opened up the project and the materials involved for public use on their website making it easier for educators to get direct practical help with regards to putting a specific theory (like IEE) into practice. Narvaez and Lapsley (2009) equate a virtuous person with an expert, they then go on to say that:

In contemporary terms, the expert has sets of procedural, declarative, and conditional knowledge that are applied in the right way at the right time ... Experts have more and better organized knowledge that consists of declarative (explicit), procedural (implicit) and conditional knowledge, much of which operates automatically. In brief, experts know what knowledge to access, which procedures to apply, how to apply them, and when. (p. 258)

What are morally virtuous people experts in? Narvaez and Lapsley (2009:258) use the American psychologist James Rest's four stages component model that held four virtues, which must be developed for a person to be morally mature and correct. In psychologists' terms, 'morally mature and correct' counts for eudemonia (i.e. the good life).

Narvaez (2006:717), formerly a church musician, furnishes each of the virtues with a moral exemplar or expert snatched from the history of Christianity; these are:

- ethical sensitivity - Mother Teresa

- ethical judgement - King Solomon

- ethical focus - Martin Luther King Jr.

- ethical action - Paul of Tarsus.

With respect to virtues themselves, Narvaez (2006:722) stated that virtues 'are patterns of behavior developed with practice, effort, and guidance from parents, educators, and mentors, until external guidance is unnecessary'. In other words, virtue development requires apprenticeship under the guidance of others. In this view, virtues are not cultivated in isolation but with the help of the community:

Moreover, virtues are not cultivated through blind obedience or rote memorization, but with guided reflection ... With guidance, children build moral responses across a variety of contexts, accumulating a repertoire of schemas and responses to apply throughout their lives. (Narvaez 2006:722)

Each of the four virtues has seven skills attached to them that you will have to master if you want to be considered a morally virtuous person. As examples, ethical sensitivity skills include:

- understanding emotional expression

- taking or considering the perspective of others

- connecting with others

- responding to diversity

- controlling social bias

- interpreting situations

- communicating effectively.

Through mutual interaction with (to develop the deliberative mind) and immersion in (to develop the intuitive mind) the skill, children will hopefully learn to solve domain problems. There are four steps to instruction and immersion, and Narvaez (2006:722) lists them as follows:

- Identification: 'Learning to see the big picture of the domain through exposure to a myriad of examples'.

- Elaboration: 'Their attention is drawn to key facts and specific detail in the domain to elaborate on their initial intuitions about the domain'.

- Procedural: 'Third, students learn specific sets of procedures to apply and practice, building procedural knowledge in the domain'.

- Execution: 'Last, students construct execution knowledge, by fine-tuning declarative, procedural, and conditional knowledge as they solve problems of different kinds in varied contexts'.

With Narvaez's approach both instinctive behaviour and rational thought (i.e. moral deliberation and imagination) receive attention when trying to foster moral development and educate towards character. Narvaez's approach ought to be helpful to churches and schools alike, especially in a time when South Africa looks to character education, but do not want to replicate older ways of educating that sometimes placed the emphasis on exhortation, memorisation and punishment.

\section{Conclusion}

To quickly recapitulate, virtue ethics (popular with ancient audiences) has made a comeback. One of the reasons for this can be traced back to an essentialist approach to knowledge that places the emphasis on society as social construct that needs to be understood within its own context. Because of this, universal rules and norms tend to lose their shine. With the rise in popularity of virtue ethics and character education, some have focused on hammering virtues into the minds of children. Whilst insights provided by researchers working in the multidisciplinary field of cognitive science shows that virtue ethics does provide a good description of human behaviour, the cultivation of moral deliberation and 
imagination cannot be ignored. Towards this end, Darcia Narvaez fashioned IEE. In the United States of America, IEE has shown itself to be a tried and tested method able to facilitate character education.

I believe that such an approach can be put to use in South Africa. The moral quandary we currently find ourselves in needs no documentation, neither the fact that by far the overall majority consider them Christian. We need to look for solutions.

In this respect, IEE need not be copied blindly. Following more of an essentialist approach, churches could take stock of what they believe to be the virtues and skills that makes for moral character in their society (following Alasdair MacIntyre's lead). The structure provided by Narvaez, along with the insights provided by researchers in the multidisciplinary field of cognitive science, can provide an adequate starting point for the growing number of Christian schools as well as churches interested in serving their community.

\section{Acknowledgements Competing interests}

The author declares that he has no financial or personal relationships which may have inappropriately influenced him in writing this article.

\section{References}

Alexander, L. \& Moore, M., 2012, 'Deontological ethics', in E.D. Zalta (ed.), The Stanford encyclopedia of philosophy, Winter 2012 Edition, viewed 21 January 2015, from http://plato.stanford.edu/archives/win2012/entries/ethics-deontological/

Beiser, F.C., 2011, The German historicist tradition, Oxford University Press, New York. http://dx.doi.org/10.1093/acprof:0so/9780199691555.001.0001

Bennardo, G. \& De Munck, V., 2014, Cultural models: Genesis, methods, and experiences, Kindle Edn., Oxford University Press, New York.
Cherry, K., 2010, The everything psychology book: Explore the human psyche and understand why we do the things we do, Kindle edn., F+W Media, Inc., Avon, understand why we do the
United States of America.

Frank, A.W., 2010, Letting stories breathe. A Socio-Narratology, Kindle edn., The University of Chicago Press, Chicago, United States of America. http://dx.doi. org/10.7208/chicago/9780226260143.001.0001

Forster, M.N., 2010, After Herder. Philosophy of language in the German tradition, Kindle edn., Oxford University Press, New York.

Greeve Davaney, S., 2000, Pragmatic historicism: A theology for the 21st Century, State University of New York Press, Albany.

Hammond, L.D., Austin, K., Orcutt, S. \& Rosso, J., 2001, Episode \#1 Introduction charter: How people learn: Introduction to learning theories, Stanford University School of Education, Stanford, United States of America.

Hauerwas, S., 1983, The peaceable kingdom: A primer in Christian ethics, University of Notre Dame Press, Notre Dame, Indiana.

Johnson, M., 2014, Morality for humans: Ethical understanding from the perspective of cognitive science, Kindle edn., University of Chicago Press, Chicago, United States of America. http://dx.doi.org/10.7208/chicago/9780226113548.001.0001

Kohn, A., 1997, How not to teach values: A critical look at character education, viewed 21 September 2014, from http://www.alfiekohn.org/teaching/hnttv.htm

Kotva, J.J., 1996, The Christian case for virtue ethics, Kindle edn., Georgetown University Press, Washington, D.C.Leavitt, J., 2011, Linguistic relativities, language diversity and modern thought, Kindle edn., Cambridge University Press, Cambridge.

Maclntyre, A., 1981, After virtue: A study in moral theory, University of Notre Dame Press, Notre Dame, Indiana.

McManus, F. \& Butler, G., 2014, Psychology: A very short introduction, Kindle edn., Oxford University Press, New York.

Medin, D.L. \& Rips, L.J., 2005, 'Concepts and categories: Memory, meaning, and metaphysics', in K. Holyoak \& B. Morrison (eds.), The Cambridge handbook of thinking and reasoning, pp. 37-72, Cambridge University Press, Cambridge.

Narvaez, D., 2006, 'Integrative ethical education', in M. Killen \& J. Smetana (eds.), Handbook of moral development, pp. 703-734, Lawrence Erlbaum Associates Publishers, New Jersey.

Narvaez, D. \& Lapsley, D.K., 2009, 'Moral identity, moral functioning, and the development of moral character', in D.M. Bartels, C.W. Bauman, Skitka, L.J. \& D.L. Medin (eds.), The psychology of learning and motivation, vol. 50, pp. 237-265, Academic Press, Burlington. http://dx.doi.org/10.1016/s0079-7421(08)00408-8

Pennington, D.C., 2012, Social cognition, Kindle edn., Routledge, London.

Sikka, S., 2011, Herder on humanity and cultural difference, Kindle edn., Cambridge University Press, Cambridge. http://dx.doi.org/10.1017/CBO9780511783012

Sloutsky, V.M., 2010, 'Perceptual categories to concepts: What develops?', Cognitive Science 34, Ohio State University, Columbus, Ohio.

Thagard, P., 2014, 'Cognitive science', in E.D. Zalta (ed.), The Stanford encyclopedia of philosophy, Fall 2014 Edition, viewed 22 January 2015, from http://plato.stanford. edu/archives/fall2014/entries/cognitive-science/

Wright, N.T., 2010, After you believe: Why Christian character matters, Kindle edn., Harper Collins Inc., London. 